send deputies, and to fill in the agency forms recently sent out or to write in and ask for forms if they have not received them.

The reason why London weighting was not pursued earlier in the year was that insufficient representatives from London turned up to press their case. When they did, very eloquently, at the last meeting of the Group Council the negotiators im mediately took London weighting to the Department of Health and Social Security, which has agreed to it in principle pending the next full pay review.

The only ultimate answer to the problem lies in participation. All hospital doctors must be seen to be attending meetings and having their say. Only then will the public, and their agents the Government, see that we mean business.-I am, etc.,

D. E. F. NEwTON

Chairman, Hospital Junior Staf Grcup Co 'nc Tynemouth,

Tyne and Wear

\section{Other Health Services}

SIR,-I feel it regrettable that public discussion about the difficulties in the Health Service suffer from two, among other, defects. In the first place criticisms of the National Health Service and suggestions of alternative designs are interpreted as a rejection of the idea of $a$ national health service and carry the odium of opposition to free medical care or social welfare as such Secondly, discussion is highly insular. It is assumed that health services elsewhere in the western world are inferior to ours and have nothing to teach us. No mention is made of the Canadian health service.

I have been impressed when, on holiday on the Continent, I have talked to working people from France, Germany, and other countries, all of whom seem pleased with their medical care. One cannot say the same for Britain. From the point of view of morale among the relevant professions and the public our "best health service in the world" must, in fact, be one of the worst. Even socialist Sweden shows no inclination to copy our design. Eastern Europe provides the nearest to our model and I understand that private practice is flourishing there.

I have recently returned from a shont trip to western Canada, where I have stayed with medical specialist friends and looked round hospitals in Vancouver, Calgary, and Edmonton. Some were Labour Party supporters before emigration, but all felt that the Canadian schemes are superior to ours. (There appears to be a widespread impression here that there is no free medical care for the whole population of Canada and that, as in the U.S.A., illness is financed by private insurance or can be ruinous.) Approximately $9 \%$ of the Canadian gross national product is spent on health care. The Federal Government directed that all provinces initiate a health scheme with certain minimal provisions. The provincial schemes differ only in such detail as the source of finance and so on. In every case the model is that of a Governmentadministered insurance practice with independent contractor status for the doctors and a fee per item of service. In British Columbia there is an income-related contribution, the lowest rate being 50 cents per month (approximately 30p), and this can be paid by social security if the person cannot afford it. Only about $5 \%$ of the population is not covered and these are mainly vagrants who have not signed the appropriate forms but can receive similar treatment to everybody else by going to the hospital casualty department, where a duty doctor in all specialties is on call to help. Such a person receives the same standard of accommodation and care as though he were registered. Almost everybody else goes to the general practitioner or specialist at private consulting rooms so that hospital outpatients have virtually disappeared. Some hospital work is for a salary or sessional fee but most is paid on the basis of consultations. All medical work and hospital beds are therefore in a sense "private" and in a sense "public." Fully private hospitals appear to be regarded as somewhat shady. No money changes hands between doctor and patient. The scheme is "policed" for abuse through the royal colleges by the method of monthly clinical audit. "Double billing" (that is, charging more than the health service fee), though legal, requires a cumbersome statutory procedure so that very few doctors bother to use it.

Therefore there is in practice a one-tier system so that all income groups attend the same doctors in the same offices and use the same hospital facilities. As independent contractors the doctors earn more but provide their own consulting rooms and do not have occupational pensions, paid holidays, and paid sick leave. This does not appear to worry them. They do have tax advantages, of course. There seems to be less administrative work than here because everyone runs his own practice. The atmosphere of freedom is most noticeable, the system being far less rigid than ours with less bureaucratic delay. To work as a specialist in a town requires admission rights to a hospital rather than appointment to a vacancy. Staffing ratios are therefore high. In Vancouver (population approximately $1 \mathrm{~m}$.) there are, among other specialties, eight qualified gastroenterologists and approximately 10 neurologists. In Leicestershire, U.K. (population approximately 700,000 ) there is one neurologist. Because of his hospital facilities the general practitioner appears to have taken over the functions of the general physician.

Though there is some grumbling that with expansion of facilities there is less time to work as one would wish (though more time than here), morale appeared very good and the general public satisfied. Having seen many British-trained doctors working happily under the system there I find it painful to hear from politicians that British doctors here cannot be trusted to operate fee per item of service because of the danger of abuse. I found myself feeling that I would welcome working in such a system, even if my level of income remained the same as now. Alas, age advances and I have probably missed the boat.-I am, etc.,

Carlton Hayes Hospital,
Narborough, Leicester

NORMAN KAYE

\section{Weakness in Negotiation}

SIR,-At the present time the most vital concept for the medical profession, both consultant and general practitioner, is that of the independent contractor-this is the foundation of a liberal profession. The root of our weakness in negotiation lies not in the personalities of our negotiators and leaders, who are often relatively publicspirited men, but with the framework within which they work.

In negotiating with the Department of Health many of them owe their position to a constituency established by the National Health Service Acts; these are the local medical committee members, and more especially those L.M.C. members elected to the General Medical Services Committee. Thus the profession does not negotiate as a free profession, but as an already bound profession.

At the moment $I$ think the B.M.A. is suffering an unmerited loss of popularity because it is being tarnished by the collaborationist policies which have their source in the L.M.C.s. First priority for the B.M.A. must be to get the L.M.C. members off the G.M.S.C.-I am, etc.,

M. J. CLAY

Butterknowle,

Butterknowle,
Bishop Auckland, Co. Durham

\section{Confinement Fee}

SIR,-I agree wholeheartedly with Dr. P. B. Bailey's remarks ( 9 November, p. 348 ) about the confinement fee for general practitioner obstetricians. To take full responsibility for a confinement, possibly undertake a surgical procedure, and be available 24 hours of the day for just $£ 3.65$ seems to $m e$ to be iniquitous.-I am, etc.,

N. E. RUST

Frimley Green,

Camberley, Surrey

SIR,-My partners and I attend the patients of other general practitioners at a local rural maternity home. Recently one of these patients needed a forceps delivery. We followed her up for six days and on the sixth day she developed a severe post-partum haemorrhage which necessitated a drip and the flying squad.

The total amount of work involved in caring for this patient was about four hours. We will be paid exactly $£ 7$ for this work In comparison, I have paid this week a bill of $£ 6.50$ for the servicing of my central heating.-I am, etc.,

Norwich

D. J. LEEMING

\section{Knocking the B.M.A.}

SIR,-An increasing number of letters in your correspondence columns recently seem to be criticizing the B.M.A. In all fairnesswould it not be reasonable/possible/ a good idea for you to indicate by the name of the writer whether he is a B.M.A. member or not?

This suggestion was brought up by a member at a recent executive committee meeting-expressing his concern at the B.M.A. being "got at" so much.-I am, etc.,

C. D. CAMPBell Buckinghamshire Division, B.M.A.

Waddesdon

near Aylesbury, Bucks 